\title{
Reply to Commentators
}

\author{
Andrés Guerrero
}

He who founds his discourse on bravado and command reveals that it contains weak reasoning.

$$
\text { -Michel de Montaigne (1585) }
$$

I begin with the commentary by João Biehl and Sebastian Ramirez. I don't know which is the author, but I know that my article has not been read as a "signifying machine," with openness toward "what it may tell," or wondering "if it works or not" (Deleuze 1990: 3-21), or simply "with openness to the existence of a third" (Biehl and Locke 2010: 347). Of course there is a lack of fit between the positions I put forward and those defended by the authors of the critique. Although our positions may differ, they are not necessarily incompatible: at least one of their several "intersections and junctions" (Biehl and Locke 2010: 347) might be revealed through a reading that is open but not a-critical. The divergence between the positions adopted by the authors and those I defend is, for me, one of the fruits of the diversity that characterizes intellectual creativity, and in particular that of history and anthropology. I believe that it is necessary to preserve that diversity with the opening of a "debate of disagreement with the prospect of agreement" (Quick guide 2011). That is, a debate that confronts positions and drives forward a dialogical dynamic such that it reaches another position, something new that differs from both points of departure, a product of the impulse given to "collective thought"
(Quick Guide 2011). The conversational procedure is something I adopt and try (with difficulty) to convert into a habitus, as I learned and practiced it in the popular debates and actions of the 15M Movement of the Indignados in the squares of Madrid.

It is unfortunate that, on reading the commentary by Biehl and Ramirez, I cannot adopt the very words which Biehl with Locke generously directed to their commentators in Current Anthropology, and which I here quote:

We appreciate how most of commentators shared what the article opened up to them, what they saw and felt in the stories and ideas that we conveyed, rather than simply projecting deficiencies and indicting the authors for failing to fulfil imagined promises. ... This active form of reading, in reappropriating the stories, makes both writer and reader newly accountable for what emerges. 'Everywhere there are starting points, intersections and junctions, that enables us to learn something new if we refuse, firstly, radical distances, secondly the distribution of roles, and thirdly the boundaries between territories' (Rancière 2009:17). ... This openness to the existence of a third, so to speak,-an it, an indefinite, neither text/performer nor reader/ spectator, but something that, in coming about in provisional encounters between them, generates new fields of understanding and possibility - is exactly what we long to see more often in interactions among anthropologists as between 
anthropologists and their interlocutors in the field. (Biehl and Locke 2010: 347)

It is quite surprising that Biehl and Ramirez should have refrained from putting into practice on this occasion (a mini-field of power games, perhaps?) the very principles that Biehl expounds so lucidly, when debating in the pages of Current Anthropology with other academics. It is obvious that, in his common sense hierarchies, he has only considered those who are academic citizens, interpares.

This micro-scene of the academic everyday is completely trivial, obvious, and unimportant. But could it not be re-thought in the perspective of anthropological fieldwork? If we reposition this anecdote, or vignette, in the context proposed by Biehl and Locke of re-founding anthropology in the direction of a process of "becoming," centered in the creativity of desire and leaving aside the relations of power, what theme for discussion does this micro-scene suggest? Clearly, it will not be a theoretical or abstract argument, just one of those questions that flourish in the mini-conjuncture, or interstices of daily exchange. Can the anthropologist evade and put aside his relations of power when he enters the field where relations with "the people," who are often in precarious circumstances, are so unequal? Can he really give primacy to the potential of desire, when in his own immediate field of daily action, the academic, he "forgot" to apply his own recommendations (no doubt completely involuntarily and with the best of intentions)? Does not this trivial "social fact of everyday life" suggest important aspects for rethinking within the proposals of João Biehl himself?

\section{"And what is writing but the return of the original as imitation to the place of origin?"}

I would like to thank Mark Thurner for his open, dialogical reading, his willingness to let himself be carried away by some of this history, and allow it to insinuate convergences, flashes. His reflection on the "gap" emphasizes the dis- tances created by slippages, the margin of play of the "misunderstandings," the abyss opened between words and things, practices and intentions. Thurner underlines the reflection that is lost in the infinite of social and personal reality, a repetition of images projected in opposite mirrors: a gap between the meaning of legal citizenship and that of common sense, between the legal prescription of equality and the power relations in the traffic of daily life, between the practice of research, the processes in the field, and the narrative woven by the anthropologist/historian. In the social processes and in the living presence of people, that hole or gap is what makes it possible for "something new to happen," the event is the opening where diversity is generated and the unforeseen becomes real. For me, as a person and in the costume of an anthropologist/historian making his voyage on the sea of life, in the passages of thought and in the adventure of narration, the lines "from which one leaves, converses and shares," the problem that confronted me, in life and in the field, had the overpowering force with which events normally impose themselves. To speak from the social, personal, and institutional dislocations: that is a dimension which, I think, Mark Thurner has read, or perhaps intuited, in my work, an empty space where something may happen and perhaps be reflected in multiple conceptual divergences in other places and studies.

\section{References}

Biehl, João, and P. Locke. 2010. Deleuze and the anthropology of becoming. Current Anthropology 51 (3): 317-351.

Deleuze, Gilles. 1990. Lettre à un critique sévère. In Pourparlers 1972-1990. Paris: Éditions de Minuit.

Montaigne, Michel de. [1585] 1991. On the lame. In the Essays: A selection, bk. III. London: Penguin.

Quick guide for the dynamization of popular assemblies. 2011. http://fromtheplazas.wordpress .com/translated-documents/statement-oncollective-thinking-assemblies-and-consensus/.

Rancière, Jacques. 2009. The emancipated spectator. London: Verso. 